\title{
Translation and cross-cultural adaptation into Brazilian Portuguese of the Measure of Parental Style (MOPS) - a self-reported scale - according to the International Society for Pharmacoeconomics and Outcomes Research (ISPOR) recommendations
}

\section{Tradução e adaptação transcultural para o português brasileiro do instrumento autoaplicável Measure of Parental Style (MOPS) utilizando as recomendações da International Society for Pharmacoeconomics and Outcomes Research (ISPOR)}

\author{
Fernanda L. C. Baeza, ${ }^{1}$ Marco A. K. Caldieraro, ${ }^{2}$ Diesa O. Pinheiro, ${ }^{1}$ Marcelo P. Fleck ${ }^{3}$ \\ 1 Universidade Federal do Rio Grande do Sul (UFRGS), Porto Alegre, RS, Brazil \\ 2 Programa de Pós-graduação em Ciências Médicas da UFRGS: Psiquiatria, Universidade Federal do Rio Grande do Sul (UFRGS), Porto Alegre, \\ RS, Brazil \\ ${ }^{3}$ Departamento de Psiquiatria e Medicina Legal, Universidade Federal do Rio Grande do Sul (UFRGS), Porto Alegre, RS, Brazil
}

Universidade Federal do Rio Grande do Sul, Hospital de Clínicas de Porto Alegre, Faculdade de Medicina, Departamento de Psiquiatria e Medicina Legal, Programa de Transtornos do Humor do HCPA (PROTHUM).

\begin{abstract}
Objective: To describe the translation and adaptation methodology for the Measure of Parental Style, a self-report instrument developed originally in English, following the International Society for Pharmacoeconomics and Outcomes Research guidelines, comparing this to other methodologies used for the same purposes. Method: Translation and Cultural Adaptation group International Society for Pharmacoeconomics and Outcomes Research guidelines were followed (preparation, first forward translation, reconciliation, back translation, revision of back translation, harmonization, cognitive debriefing, revision of debriefing results, syntax and orthographic revision, final report). Conclusion: A careful and qualified cross-cultural translation and adaptation of an instrument contribute for measuring what it is designed to measure across cultures. Presenting this process, besides its final product, provides the opportunity that this experience could be replicated for adaptation of other instruments.
\end{abstract}

Descriptors: Methodology; Translating; Adaptation; Cross-cultural comparison; Guidelines as topic

\section{Introduction}

The relationship with parents during childhood plays a definite role in the development of psychiatric disorders and emotional interactions in adult life, particularly major depression. ${ }^{1,2}$

\section{Resumo}

Objetivo: Descrever a metodologia de tradução e adaptação do Measure of Parental Style, instrumento autoaplicável desenvolvido originalmente em inglês, segundo as recomendaçôes da International Society for Pharmacoeconomics and Outcomes Research, analisando-a criticamente em relação a outras metodologias utilizadas para o mesmo fim. Método: Foram utilizadas as diretrizes do Translation and Cultural Adaptation group, vinculado à International Society for Pharmacoeconomics and Outcomes Research, seguindo os passos: preparação; primeira tradução; reconciliação; retrotradução; revisão da retrotradução; harmonizaçāo; estudo piloto; revisão dos resultados do estudo piloto; revisão sintática e ortográfica; relato final. Conclusão: Uma tradução e adaptação transcultural criteriosa e de qualidade contribui para que o instrumento possa medir o que se propõe em diversas culturas. Apresentar este processo, assim como seu produto final, possibilita a utilização desta experiência na adaptação de outros instrumentos.

Descritores: Metodologia; Tradução (processo); Adaptação; Comparação transcultural; Guias como assunto

The Measure of Parental Style (MOPS) was originally developed in English to measure the contribution of parents' behavior in the genesis of some psychiatric disorders, build as an enhancement of Parental Bonding Instrument (PBI). ${ }^{1}$ It is a self-report instrument,
Submitted: December 15, 2008

Accepted: October 22, 2009
Correspondence

Fernanda Lucia Capitanio Baeza

Rua Felipe Camarão, 312/302

90035-141 Porto Alegre, RS, Brazil

E-mail: fernanda.baeza@gmail.com 
with 15 Likert-type items $(0-3)$ containing statements about relationship with parents during a person's first 16 years. The items are divided into three subscales: indifference, abuse and overcontrol. There is no cutoff point; the analyses are made by comparing scores of different groups. In addition to proving capable of identifying physical abuse during childhood, MOPS also distinguished melancholic and non-melancholic subtypes in major depressive disorder, whose scores were significantly higher. ${ }^{1}$

The cross-cultural adaptation of a research instrument is an important step in a scientific investigation. Errors at this stage may misrepresent the original intent of the instrument, compromising the study's validity and reliability. ${ }^{3}$

The translation and adaptation methods of Health measurement instruments are widely heterogeneous. Although some steps are deemed important by most authors, there is no consensus about the most appropriate methodology. ${ }^{4}$ An analysis of six methods of cross-cultural translation and adaptation came to the conclusion that a simple translation, despite being quick and inexpensive, does not check the semantic equivalence between the original and the translated instrument. ${ }^{5}$ From the 17 adaptations analyzed by Guillemin et al., only six employed back translation. ${ }^{6}$ The method proposed by Flaherty considered five aspects of crosscultural equivalence: content; semantics; technique; criterion and conceptual aspect. ${ }^{\top}$

The Translation and Cultural Adaptation group (TCA group), linked to the International Society for Pharmacoeconomics and Outcomes Research (ISPOR), performed a review of evidences of current practices in translation and adaptation of instruments and in 2005, published guidelines describing the steps to adapt self-report instruments. ${ }^{8}$ Since its publication, its guidelines were followed to produce versions of instruments in at least six languages, in various health areas.

The purpose of this study is to describe the steps of cross-cultural translation and adaptation of MOPS into Brazilian Portuguese employing the methodology proposed by the TCA group, to make a critical comparison of them with other methodologies referred to in the literature and to present the adapted version of MOPS in Brazilian Portuguese.

\section{Method}

The TCA group guidelines for translation and adaptation of self-report instruments ${ }^{8}$ were followed, according to the following steps:

1) Preparation: authorization by the authors of the original instrument; selection of translators.

2) First translation: production of two independent versions in the target language (V1 and V2).

3) Reconciliation: synthesis of V1 and V2.

4) Back translation: done by a translator who had no contact with V1 an V2.

5) Revision of back translation: comparing back translation with the original.

6) Harmonization: comparing back translated version with other back translations made based on the same instrument.
7) Cognitive debriefing: application of the instrument on a sample.

8) Revision of debriefing results.

9) Syntax and orthographic revision.

10) Final report.

This project was approved by the Research Ethics Committee of Hospital das Clínicas de Porto Alegre under number 06-024.

\section{Findings}

\section{Preparation}

The process starts with the authorization given by the authors of the original instrument. The execution was carried out by the Brazilian research group and a professional translator not linked to the research group, with the assistance of the author of the original instrument.

\section{First translation}

The translators must be native speakers of the target language, preferably residents of the target country and fluent in the instrument's original language. Four people who met these requirements, in two pairs, made independent translations (V1 and V2). The production of two independent versions prevents the translated instrument from containing the linguistic style of a single person and facilitates the detection of errors and diverging interpretations of ambiguous terms, reducing potential biases. ${ }^{8}$

\section{Reconciliation}

The discrepancies between independent translations are solved and a third version is produced (V3). There is no consensus in the TCA group as to who should complete this step. It may be done 1) by a native speaker of the target language not involved in the preparation of $\mathrm{V} 1$ and $\mathrm{V} 2,2$ ) by the translators who produced $\mathrm{V} 1$ and $\mathrm{V} 2$, in addition to the person in charge of the project in the target country, 3) by the person appointed to conduct the cognitive debriefing. We chose the first option, since potential translation biases in V1 and V2 could be maintained if in the event the people who made those translations took part in the reconciliation process. The person in charge of the project in Brazil met the requirements of being a native Portuguese speaker and not having taken part in the first translations. In every item, the most colloquial expression was chosen. Table 1 summarizes the results of each step.

\section{Back translation}

Back translation is the quality control of the produced version. It was performed by an outsourced translator, not linked to the research group, who was not supposed to know the original instrument or the first translations.

\section{Revision of back translation}

The project coordinator in Brasil and the author of the original instrument have compared the original instrument with the back translation. Despite literal differences when compared to the original, it was verified that the back translated version was equivalent to the original version. 


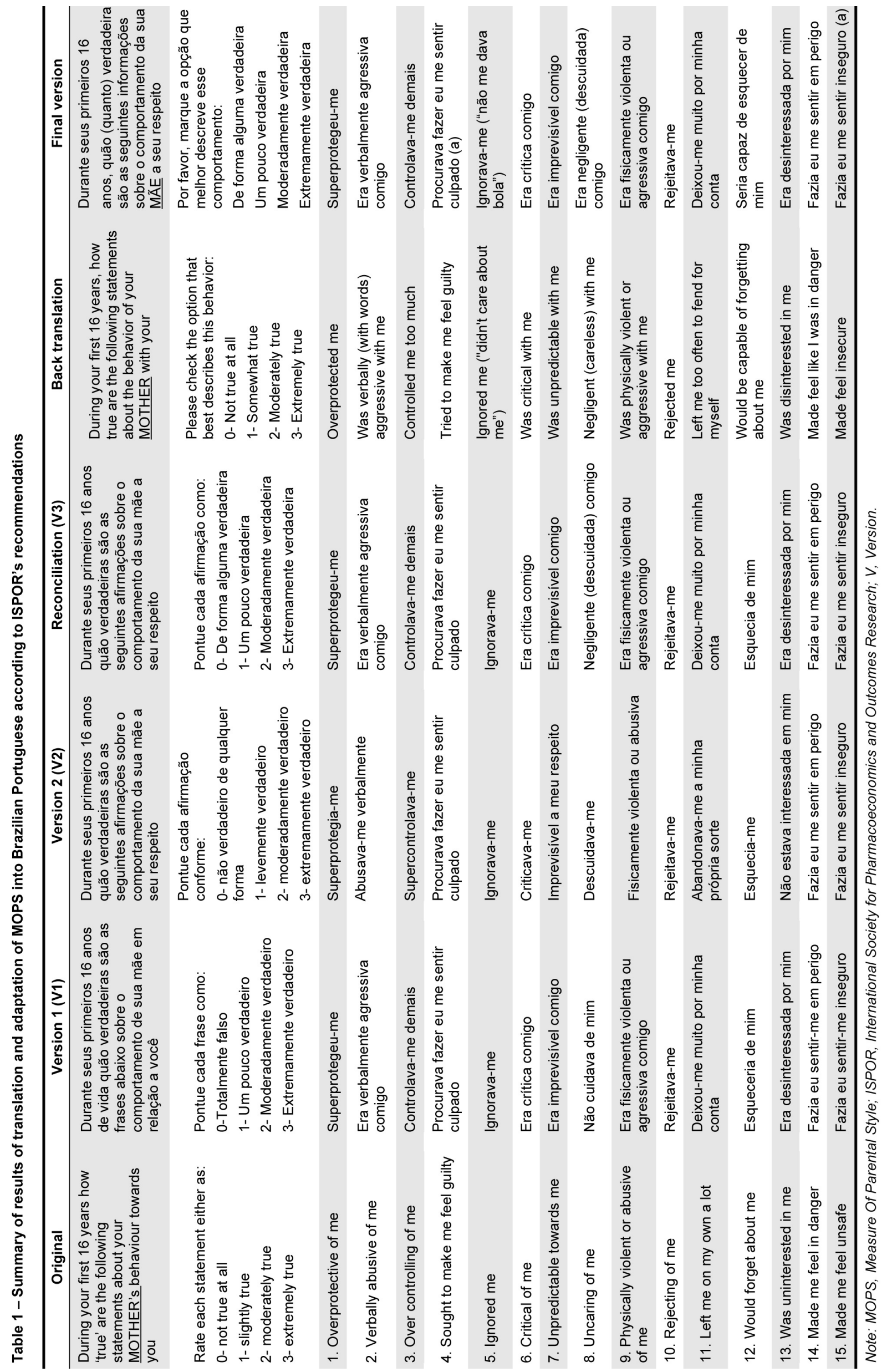




\section{Harmonization}

When an instrument is being adapted to various languages, the back translations produced in the different target countries are compared. This step did not apply to MOPS.

\section{Cognitive debriefing}

Cognitive debriefing is essential to assess the level of understanding and the semantic equivalence of the translated version, in addition to highlighting inappropriate or confusing terms.

The Brazilian version of MOPS was applied to five depressed outpatients whose native tongue is Portuguese. For each item it was asked what the patient understood of it, if there were any difficulties or suggestions.

\section{Revision of debriefing results}

The debriefing results were revised and the modifications suggested by patients were added to the reconciled version.

\section{Syntax and orthographic revision}

The purpose of the syntax and orthographic revision is to correct errors in the instrument's final wording.

\section{Final report}

The TCA group recommends that a detailed report of the process should be prepared to facilitate future adaptations of the same instrument to other cultures, as well as to enable the experience to be transferred to other self-report instruments. ${ }^{8}$

\section{Discussion}

This project describes the production of the Brazilian Portuguese version of MOPS using the method proposed by the TCA group. This methodology proved appropriate due to its strict, sequential and clear structure of steps that are easy to apply.

This method has similarities and differences when compared to other processes described to adapt instruments to Brazilian Portuguese. The description of the adaptation of the Abuse Assessment Screen (AAS) ${ }^{9}$ and Social Phobia Inventory $(\mathrm{SPI})^{10}$ focused mainly on the semantic equivalence between the original and the adapted version.

In the AAS adaptation, the first translations also gave rise to two independent versions, which were back translated separately and then analyzed in terms of semantic equivalence. ${ }^{9}$ The analysis of two back translations is more complex than the method proposed by the TCA group, and probably produces similar results in this regard.

The Brazilian version of AAS underwent a cognitive debriefing; however, it was not evaluated by the original author. The participation of the authors of the original instrument, particularly in the evaluation of the back translation, helps to ensure that the adapted version is compatible with the original.

The description of the SPI adaptation includes two independent translations and back translations, evaluated in terms of semantic, idiomatic and conceptual equivalence; preparation of a consensual version; approval by the authors of the original instrument; and application of the instrument in a target audience sample. ${ }^{10,11}$ The procedure used for this process follows most of the steps recommended by the TCA group, in addition to being more detailed in linguistic terms.

The Brazilian version of SPI was evaluated in terms of internal coherence and validity. Even when an instrument has been validated in its original language, the adapted version must be validated in the target culture. ${ }^{12}$ These procedures have not been carried out yet in the Brazilian version of MOPS.

For the translation and adaptation of the Obsessive-Compulsive Inventory and Obsessive-Compulsive Inventory-Revised scales, the steps followed were similar to those proposed by the TCA group. However, back translation and evaluation by the original author were performed after testing the scales on research subjects. ${ }^{13}$

It is clear that some steps of the process are common to the various methods revised, such as independent translations. One of the advantages of following ISPOR guidelines lies in their wide applicability, since it provides a detailed guide for each step of the process.

Such guidelines do not cover linguistic issues per se, such as those addressed in more detail by other works. In this method, semantic and conceptual equivalences are evaluated in the reconciliation, back translation, revision, harmonization and cognitive debriefing. Despite eliminating gross linguistic issues, this approach is insufficient to cover every semantic, idiomatic and conceptual aspect. The potential impact of this gap would be a loss in content-related validity. More specific issues about these aspects are better addressed by other methods, particularly the method proposed by Flaherty, ${ }^{7}$ which, due to its great complexity, has not been widely used in cross-cultural studies.

The report on the translation and adaptation of MOPS is an example of the application of the TCA group method in Brazil. The experience of following this guideline showed that its main merit is to reconcile methodological rigor with practical simplicity. Therefore, a quality cross-culturally translated and adapted version is obtained in a few weeks. We conclude that this method has the necessary requirements to be widely used in our environment. MOPS is an enhanced version of PBI, already validated in its original language. Despite the fact that its Brazilian version still lacks a final validation, we believe it is suitable for application on the Brazilian population. 


\section{Disclosures}

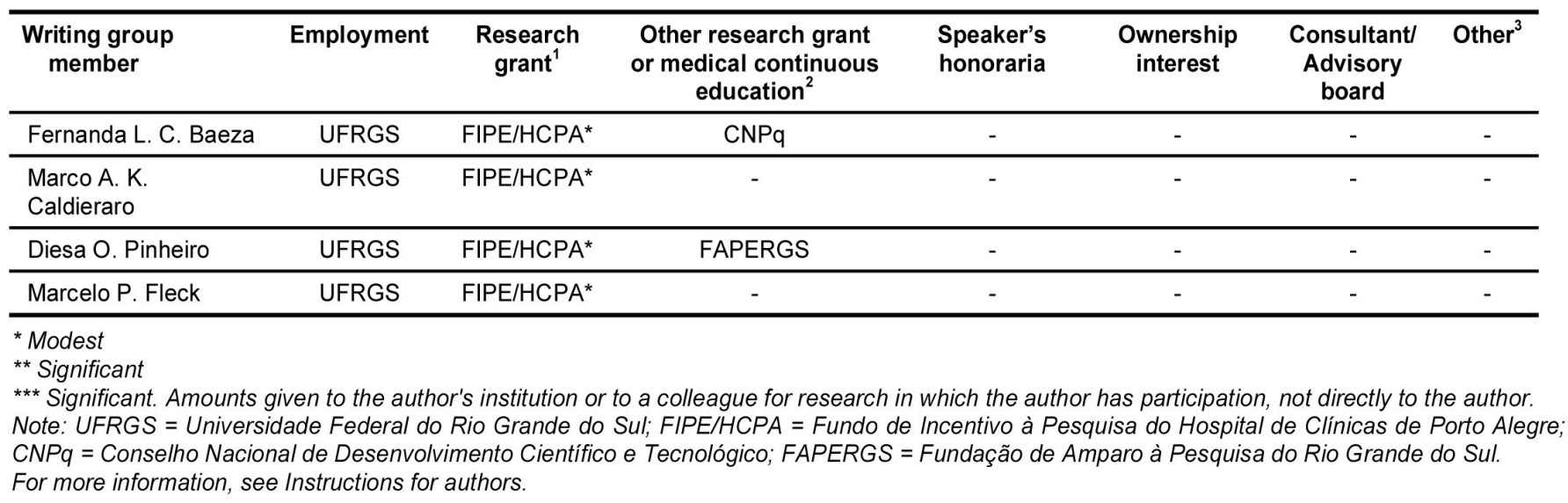

References

1. Parker G, Roussos J, Hadzi-Pavlovic D, Mitchell P, Wilhelm K, Austin MP. The development of a refined measure of dysfunctional parenting and assessment of its relevance in patients with affective disorders. Psychol Med. 1997;27(5):1193-203.

2. Parker G, Hadzi-Pavlovic D, Greenwald S, Weissman M. Low parental care as a risk factor to lifetime depression in a community sample. $J$ Affective Disord. 1995;33(3):173-80.

3. Chang AM, Chau JP, Holroyd E. Translation of questionnaires and issues of equivalence. J Adv Nurs. 1999;29(2):316-22.

4. Acquadro C, Conway K, Hareendran A, Aaronson N; European Regulatory Issues and Quality of Life Assessment (ERIQA) Group. Literature review of methods to translate health-related quality of life questionnaires for use in multinational clinical trials. Value Health. 2008;11(3):509-21.

5. Maneesriwongul W, Dixon JK. Instrument translation process: a methods review. J Adv Nurs. 2004;48(2):175-86.

6. Guillemin F, Bombaridier C, Beaton D. Cross-cultural adaptation of a healthrelated quality of life measures: literature review and proposed guidelines. J Clin Epidemiol. 1993;46(12):1417-32.

7. Flaherty JA, Gaviria FM, Pathak D, Mitchell T, Wintrob R, Richman JA, Birz $\mathrm{S}$. Developing instruments for cross-cultural psychiatric research. J Nerv Ment Dis. 1988;176(5):257-63

8. Wild D, Grove A, Martin M, Eremenco S, McElroy S, Verjee-Lorenz A, Erikson P; ISPOR Task Force for Translation and Cultural Adaptation. Principles of good practice for the translation and cultural adaptation process for patient-reported outcomes (PRO) measures: report of the ISPOR Task Force for translation and cultural adaptation. Value Health. 2005;8(2):94-104.

9. Reichenheim ME, Moraes CL, Hasselmann MH. Semantic equivalence of the Portuguese version of the Abuse Assessment Screen tool used for the screening of violence against pregnant women. Rev Saude Publica. 2000;34(6):610-6.

10. Vilete L, Figueira I, Coutinho E. Adaptação transcultural para o português do Social Phobia Inventory (SPIN) para utilização entre estudantes adolescentes. Rev Psiquiatr RS. 2006;28(1):40-8.

11. Osório Fde L, Crippa JA, Loureiro SR. Cross-cultural validation of the Brazilian Portuguese version of the Social Phobia Inventory (SPIN): study of the items and internal consistency. Rev Bras Psiquiatr. 2009;31(1):25-9.

12. Fachel JM, Camey $S$. Avaliação psicométrica: a qualidade das medidas e o entendimento dos dados. In: Cunha JA. Psicodiagnóstico V. Porto Alegre: Artes Médicas; 2000. p.158-70.

13. Souza FP, Foa EB, Meyer E, Niederauer KG, Raffin AL, Cordioli AV. Obsessivecompulsive inventory and obsessive-compulsive inventory-revised scales: translation into brazilian portuguese and cross-cultural adaptation. Rev Bras Psiquiatr. 2008;30(1):42-6. 